\title{
Peace Engineering: Investigating Multidisciplinary and Interdisciplinary Ef- fects in a Team-Based Course About Drones
}

\section{Dr. Elizabeth A. Reddy, University of San Diego}

Elizabeth Reddy is a post-doctoral research associate at the University of San Diego's Shiley-Marcos School of Engineering. She is a social scientist, holding a PhD in cultural anthropology from the University of California at Irvine and an MA in Social Science from the University of Chicago. She is Co-Chair of the Committee for the Anthropology of Science, Technology and Computing in the American Anthropological Association. She studies experts and their work in relation to environments, technologies, and human lives. Her current research projects deal with earthquake risk management technology in Mexico and the United States, environmental data justice in the US/Mexican borderlands, and the development and practice of engineering expertise.

\section{Dr. Gordon D Hoople, University of San Diego}

Dr. Gordon D. Hoople is an assistant professor of general engineering at the University of San Diego. His research interests lie in microfluidics, rapid prototyping, genomics, engineering ethics, and engineering education. He earned his MS and PhD in mechanical engineering from University of California, Berkeley and a BS in engineering from Harvey Mudd College.

\section{Prof. Austin Choi-Fitzpatrick, University of San Diego}

Austin Choi-Fitzpatrick is a writer and professor at the Kroc School of Peace Studies at the University of San Diego. His work focuses on politics, culture, technology, and social change. He is the author of What Slaveholders Think (2017, Columbia) and co-editor of From Human Trafficking to Human Rights (2012, Pennsylvania). His newest book, Protest Tech, explores the ways tools and technologies are used to bring social change.

\section{Dr. Michelle M. Camacho, University of San Diego}

Michelle Madsen Camacho is Professor in the Department of Sociology \& Faculty Administrator at the University of San Diego and is a former Fellow of the American Council on Education. Her research focuses on inequities in STEM education using quantitative and qualitative research methodologies and theories from interdisciplinary sources including cultural studies, critical race, gender and feminist theories. Her book, the Borderlands of Education, is co-authored with Susan Lord, Professor of Electrical Engineering. Camacho is affiliated faculty with the Department of Ethnic Studies, Women's and Gender Studies, and the School of Peace and Justice. 


\title{
Peace Engineering: Investigating Multidisciplinary and Interdisciplinary Effects in a Team-Based Course About Drones
}

\begin{abstract}
The practice of engineering often involves problem solving in multidisciplinary and interdisciplinary teams. Undergraduate engineering students often are trained in disciplinary concepts and techniques of their specializations, but rarely given opportunities to reflect upon how they work with collaborators. Here, we discuss a course that brings students from engineering and non-engineering fields together to grapple with a technical and conceptual challenge: designing and building drones for humanitarian purposes. This paper describes an "Engineering Peace" course and discusses preliminary findings from surveys, focus groups, and observations regarding the course's effects on students' multidisciplinary and interdisciplinary skills. This material allows us to analyze the emergence of professional formation as engineers and non-engineers work together. While we understand this study to be limited in scope, the feedback provides preliminary evidence for collaborative research across disciplines and how professional skills are fostered in the classroom.
\end{abstract}

\section{Introduction}

Undergraduate engineering students are often trained in disciplinary concepts and techniques of their specializations, but are rarely given opportunities to work with collaborators from different disciplines. In Gary Lee Downey's words, the very educational processes “producing engineers as outcomes" [1] may neglect key professional skills that those engineers need.

Skills that relate to collaborating with peers in different disciplines are increasingly necessary for practicing engineers. While research has indicated that working on teams with others who bring different skills and specialties to the table may be crucial to engineering practice, these multidisciplinary opportunities are the exception, not the norm [2]. While training students to function on a multidisciplinary team is part of ABET criteria [3], students may not have opportunities to develop expertise in these areas. This lacuna is easier to identify than it is to remedy, not only because such prospects compete for students' time and attention, but also because faculty may lack support to develop these skills within the course. At many universities, undergraduate students have few opportunities (aside from perhaps a capstone project in their 4th year where they might work with an engineer from another discipline) to work with peers who have different specialties.

At the University of San Diego, which has a strong Liberal Arts tradition, all undergraduate engineering students graduate with a BA/BS degree and are required to take roughly 10 courses outside of the Shiley Marcos School of Engineering. This requirement helps students think broadly and critically and sometimes brings them into contact with students who hold dramatically different perspectives than they do. Unfortunately, students tend to not recognize 
how these courses connect back to their identities as engineers. While these classes sometimes involve team work, students do not work on projects where they exercise their identity as an engineer. For this reason we developed a course on "Engineering Peace." This class was part of a broader effort supported by a REvolutionizing Engineering and Computer Science Departments NSF grant to use team-taught courses to help students think about approaching engineering in new ways. This course provides an educational intervention that merges the social with the technical within the Shiley Marcos School of Engineering, providing engineering students with an opportunity to work closely with teammates of different disciplinary training.

While a course involving intensive, semester-long collaborations across disciplines promises benefits for our students, their experiences are not monolithic. Here, we reflect on our students' approaches to and reflections on their learning experiences in this course. We draw on both quantitative and qualitative data and contextualize student self-assessment with our own observations to address how their learning experiences were situated, to use Lave and Wenger's term [4],[5] in students' physical and conceptual experiences in the course.

\section{On Collaboration Across Disciplines}

Different disciplines often involve varying epistemological orientations to problem solving, which can make teamwork across disciplines incredibly rich, as well as deeply challenging, for participants [6],[7]. While research in engineering education celebrates the utility of collaboration across disciplines, the forms this collaboration takes varies tremendously. Two common concepts used to address this kind of teamwork across disciplines are multidisciplinarity and interdisciplinarity. The two concepts have a great deal common, but may entail slightly different outcomes for participants and for their projects.

Briefly, in multidisciplinary work, collaborators work together on a problem. Each brings expertise, but, as Borrego and Newswander explain in their overview of cross-disciplinary engineering collaboration, "collaborators leave the project without having learned much about the other discipline(s). Each researcher continues on his or her own independent trajectory, unchanged by the experience [8]." This means that, while multidisciplinary work brings together people with different ways of conceptualizing and operating on problems, each takes on their specialized tasks without necessarily exchanging a great deal of information about those responsibilities in the process. Researchers understand multidisciplinary collaborators to maintain their own disciplinary lenses and commitments, and make a distinction between multidisciplinary collaboration and interdisciplinary collaboration in this respect [9],[10].

In contrast, interdisciplinary work involves more thorough collaboration, and sharing of knowledge rather than division of tasks. "At the end of a truly interdisciplinary collaboration, each collaborator is changed by the experience," Borrego and Newswander summarize [8], see also [7],[9],[11]. Facilitating this kind of transformative experience as well as the development of 
all-important project management and teamwork skills for students can be deeply attractive for educators who hope to prepare students for their future status as successful professionals.

However, interdisciplinarity can be difficult to foster in the classroom. The term

"interdisciplinary" may be used to refer to a process (for example, a multidisciplinary teamwork practice that involves discussion and collaborative problem-solving), an outcome (a solution to a problem that incorporates insights from different disciplines), or even an effect for participants (a transformation in participants' perspective after collaborative work with colleagues from other disciplines). Some of these can be difficult to track as learning outcomes [10],[12].

Engineering educators have developed a number of experimental pedagogical interventions to teach the kinds of teamwork that could become interdisciplinary, involving writing and dramatic performance [12], research experience [13], and workshops on crucial team work skills [14].The course we describe here is part of a robust movement in the field that seeks to help prepare students for their careers as holistic engineers, with interest in the socio-technical context of their knowledge.

\section{Methods}

\section{Student Population}

Dr. Gordon Hoople, an Assistant Professor in the General Engineering Department of University of San Diego's Shiley Marcos School of Engineering partnered with Dr. Austin Choi-Fitzpatrick, an Assistant Professor in the Kroc School of Peace Studies and an Associate Professor at the University of Nottingham. The aforementioned NSF grant, "REvolutionizing Engineering and Computer Science Departments" with support from their respective Deans, facilitated the creation of a course, Engineering Peace. The course brings together undergraduate students from disparate fields to grapple with a technical and ethical challenge: designing and building drones for social good [15].

In the fall of 2017, twenty-four students (14 engineers and 10 non-engineers) participated in this class. Students had some experience in their chosen disciplines; there were no first year college students. Engineers were all studying Mechanical Engineering. The population was roughly divided between graduate students (8), 5th year seniors (6), seniors (4), juniors (5), and one brave sophomore (1).

\section{Background}

As described by Hoople and Choi-Fitzpatrick in a work in progress at ASEE in 2017 [16], the course that these students participated in was organized around objectives that included student learning about working in teams and collaborating while building drones. 
The output of each team was a jointly-constructed drone and a team-designed plan for a "prosocial drone"- that is, a design that would somehow have a positive impact on society. Students were challenged to wrestle with what it means for something to be pro-social. In the syllabus students were alerted to the ways that this class was likely to be different than others that they had taken before.

As Hoople and Choi-Fitzpatrick describe it, the course was divided into two general sections: a series of lectures and discussions, focusing on theory, followed by an emphasis on building and designing.

Focus in Engineering Peace Throughout the Semester

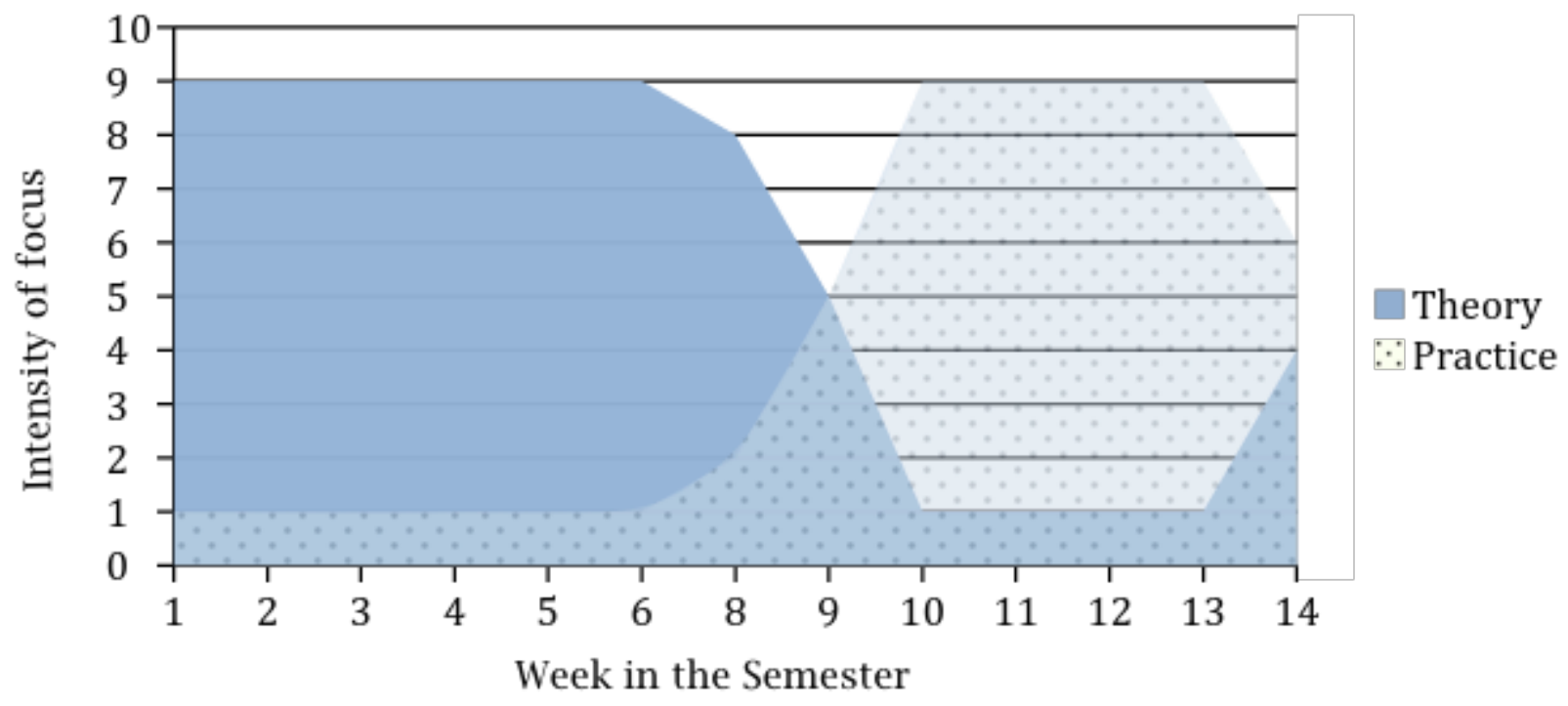

Figure 1: Over the course of the term, the ratio of time spent on lecture and discussion was reduced, and the amount of time spent on projects increased. Units of the "intensity of focus" axis are arbitrary, and developed to communicate about the course to a general audience.

In the 3rd week of the semester, students were organized into six teams. Each team contained both engineers and non-engineers. In these teams, the students performed a number of activities together in teams including guided brainstorms related to the politics of technology, social justice, social innovation and about the kinds of pro-social drones that they could build.

In the drone building processes, it was a requirement of the course that all students, engineers and non-engineers, participate in every part of the assembly process. 


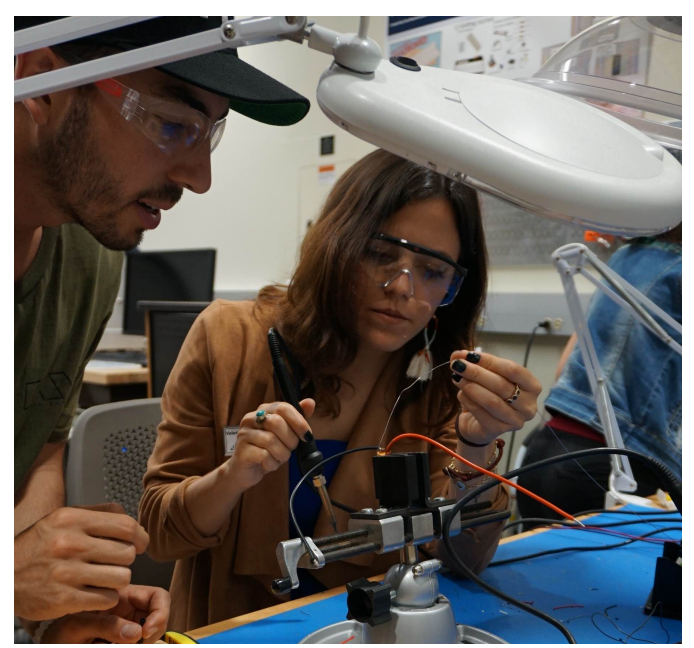

Figure 2: Engineers and non-engineers worked on drone assembly in class.

In the 5th week of the semester, students began to address the drones. Students received a collection of drone parts and, over the course of three class periods, they soldered wires, laser-cut wooden components, programmed the drone to respond to a controller, and refined the control system through open source software. In the 8th week, they took their drones flying at a local hobbyist air field.

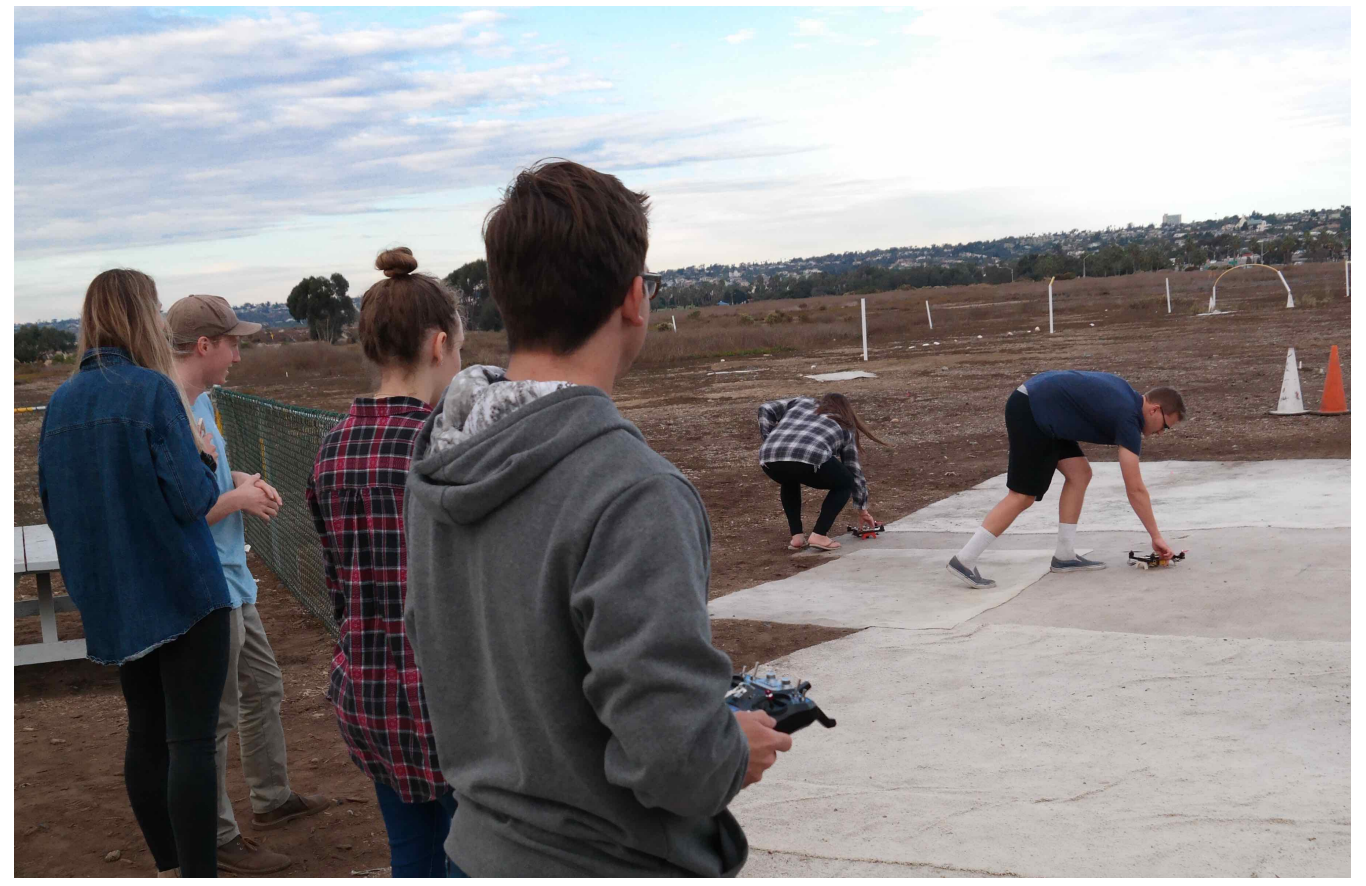

Figure 3: Teams flew the drones that they had assembled.

The hands-on knowledge about drones that students were gaining informed their work designing a pro-social drones. As they started building their drones, in the 5 th week of the class, they began to develop a proposal for how to use a drone to have a positive impact on society. They explored 
the broader context and potential confounding factors. This process resulted in an actionable product in light of the technical, economic, legal, and social factors and contexts that they encountered. As they finished building their drones, in the 9th week of class, they turned their attention back to this output. These plans were modified and finalized before the team presented the final concept to a panel of expert judges from across University of San Diego and industry, including a retired US Navy Drone pilot.

Student plans for pro-social drone payloads included several drones equipped with cameras: including one designed to help identify Palm Weevil infestations, one designed to find boats of refugees in trouble on the Mediterranean Sea, and one designed to support Ski Patrol rescue efforts. Other plans had drones equipped with a metal detector to find unexploded ordinance in Afghanistan, drones armed with tranquilizers to support park ranger anti-poaching work among dangerous large animals, and drones with heat sensors and alarms to alert people living in dense and highly flammable refugee settlements in Thailand to fires before they could spread very far.

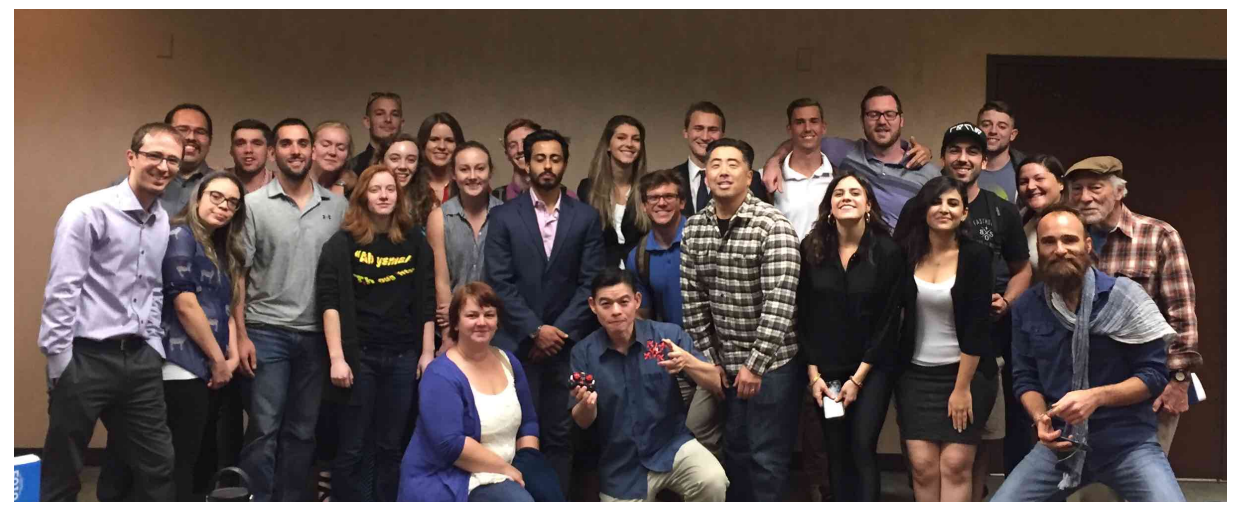

Figure 4: Teams presented plans for the pro-social drones that they had developed together. Above, they are photographed with the expert judges to whom they presented their final designs.

\section{Data Collection}

We triangulated quantitative survey data, student focus group data led by Dr. Reddy, and observational data in order to evaluate the course given the objectives that each student learn about working in teams and collaborating while building drones. The University of San Diego granted IRB approval.

\section{1) Pre- and Post- Class Survey}

In a survey of students before and after their class experience, they were asked a number of questions related to team work. These questions were asked again in a post-survey, along with additional items asking students to reflect on the impact that this class had for them, and particularly useful aspects of the course.

2) In-Class Observation 
Drs. Hoople and Choi-Fitzpatrick wrote reflections on the class progress regularly throughout the course. When the students began to build their drones, Dr. Reddy joined them to observe student work practices. Dr. Reddy also participated in a class field trip to fly the drones that they had constructed and their final presentations of their plans for pro-social drone payloads. Further, video cameras (without audio) were placed throughout the classroom, positioned in places that made it possible to capture student interactions.

\section{3) Post-Class Focus Group}

In the final days of the class, Dr. Reddy conducted a focus group with each team. These focus groups lasted between 15-30 minutes. They were shown a short video of themselves, working together on the drone project. Then they were asked to respond to a series of prompts to encourage them 1) to discuss their experience working together 2) to discuss course themes and what they felt that they learned 3) to think about the course's implications in their futures. The focus groups were semi-structured to stimulate student conversation and allowed the researcher to follow up on themes and concepts that students brought up in the moment.

\section{Results}

Student self-assessment did not show much change between pre- and post-surveys, although the survey revealed that students understood the course to have had a strong positive affect on their abilities and comfort with team projects. Students' experiences with course objectives (that each student learn about working in teams and collaborating while building drones) and team outputs (a jointly-constructed drone and a team-designed plan for a pro-social drones) are evident based on focus group and observational data. Focus group data is particularly useful for allowing teams to talk together about common experiences or issues of concern [17]. But socially difficult issues, or issues that might be awkward to discuss, may be avoided in the context of a focus group. For this reason, observational data is also brought to bear.

\section{Survey Data}

Only twenty of the twenty-four students enrolled in the course completed both a pre- and postcourse survey (14 engineers and 6 non-engineers) and this analysis focuses on those responses. Survey questions focused particularly on course objectives (that each student learn about working in teams and collaborating while building drones).

Broadly, students' responses to questions about the comfort they felt regarding interdisciplinary work did not change a great deal between pre- and post-class surveys. This was not unexpected, as we anticipated that the students would feel confident coming into the course and then discover interdisciplinary work is considerably harder than they realized. Some of these high selfassessments may be an example of a Dunning-Kruger Effect, in which, as Dunning explains, "poor performers ... seem largely unaware of just how deficient their expertise is [18]." In light of the challenges that comparing students' self-assessment could pose, we also included 
reflective questions in the post- class survey, asking students to consider the course's impact for them. In these questions, the students generally reported the course had a substantial impact on improving their comfort and abilities with skills related to interdisciplinary team work.

How capable do you feel in describing the disciplinary lens/perspective of your degree (major or masters)?

Students began and ended the class with a sense of their disciplinary backgrounds (see Table 1). On a 5 point Likert scale (where 1 was Very Incapable, a 2 was Somewhat Incapable, a 3 was Neither Capable nor Incapable, a 4 was Somewhat Capable, and 5 was Very Capable) engineers rated themselves, on average, around 4.5, while non-engineers rated themselves, on average, 4.3 - both between Very Capable and Somewhat Capable - as the class began. The small difference between the average of the engineers' responses and the average of the non-engineers' responses might be explained in part by the fact that 9 of the 10 non-engineers were enrolled in a newly-established one-year MA program in the Kroc School of Peace Studies without a singular disciplinary identity. Nonetheless, we understand these responses on the part of both engineers and non-engineers to indicate that each group had some sense of the kind of perspective or way of looking at the world that they brought to class. This sense of their own identity would form the basis for understanding their experiences working across disciplines in the course.

Table 1: Students' feelings of capability describing their own disciplinary lens in the pre-class survey.

\begin{tabular}{|l|l|}
\hline & $\begin{array}{l}\text { How capable do you feel in } \\
\text { describing the disciplinary } \\
\text { lens/perspective of your } \\
\text { degree (major or } \\
\text { masters)? }\end{array}$ \\
\hline Engineer Average & \multicolumn{1}{|c|}{4.5} \\
\hline Non-Engineer Average & 4.3 \\
\hline
\end{tabular}

Students were asked to assess their ability and comfort with such teamwork-related skills as synthesizing information from across multiple disciplines, communicating with colleagues from other disciplines, and comfort with planning and implementing projects in an interdisciplinary team environment. These questions were not as revealing of change as we had hoped they might be, however.

Students, both engineers and non-engineers, began and ended the class confident in their abilities to synthesize information and comfortable with their ability to communicate with their colleagues. We consider both of these factors to be important for success in teamwork across disciplines (see Table 2). 
There appears some positive change here: engineers' average self-rating improved by .2 on the topic of synthesizing information and .1 on the topic of planning and implementing projects on our 5-point Likert scale. Non-engineers rated themselves, on average, slightly less comfortable working in multidisciplinary teams and planning and implementing projects in interdisciplinary team environments than engineers did ("Somewhat Comfortable," or a 4 on the Likert scale), and their average self-rating improved to the level of the engineers' in the post-class survey (a 4.5, in each case).

Table 2: Students' feelings of comfort working on multidisciplinary teams before and after the class

\begin{tabular}{|l|r|l|l|}
\hline & $\begin{array}{l}\text { How comfortable do you feel } \\
\text { about your ability to synthesize } \\
\text { information from across } \\
\text { multiple disciplines? }\end{array}$ & $\begin{array}{l}\text { How comfortable do you feel } \\
\text { about your ability to } \\
\text { communicate with colleagues } \\
\text { from other disciplines? }\end{array}$ & $\begin{array}{l}\text { How comfortable are you with } \\
\text { planning and implementing } \\
\text { projects in an interdisciplinary } \\
\text { team environment? }\end{array}$ \\
\hline Engineer Average Pre-Class & 4.3 & 4.7 & 4.4 \\
\hline Engineer Average Post-Class & 4.5 & 4.7 & 4.5 \\
\hline Non-Engineer Average Pre-Class & 4.0 & 4.7 & \\
\hline $\begin{array}{l}\text { Non-Engineer Average Post- } \\
\text { Class }\end{array}$ & 4.5 & 4.7 & \\
\hline All Average Pre-Class & 4.2 & 4.7 & \\
\hline All Average Post Class & 4.5 & 4.7 & 4.5 \\
\hline
\end{tabular}

The thing to note about these responses is that they were high in both pre-and post- class surveys. The responses tallied in Table 2 suggest some small increases in students' assessment of their comfort to synthesize information and of their comfort planning and implementing interdisciplinary projects between pre-class and post-class surveys.

A two-tailed paired T test was used to assess with respect to a null hypothesis that shifts could be produced by chance. This test was chosen over ANOVA because of the relatively small population of data available for evaluation. Overall, with respect to all students' reported comfort with synthesizing information from across multiple disciplines in the post-class survey, communicating with colleagues from other disciplines both before and after the class, and planning and implementing projects, the test demonstrated a p-value of $0.030,1$, and 0.163 , respectively. If we set the measure of statistical significance at less than $\mathrm{P}=.05$, that is, $95 \%$ confidence that that such a result could not be produced by chance, then we can be most confident that the shift in average responses to the question regarding synthesizing information should be considered statistically significant. Responses to the question about communication saw no change between pre- and post- class responses, and this is reflected by its p-value of 1 .

When a two-tailed paired $\mathrm{T}$ test was used to assess changes in just the engineers' responses to these questions between pre-class survey and post-class survey, the test demonstrated p-values of $0.189,1$ and 0.583 , none of which are within the threshold of $\mathrm{P}=0.05$ or $95 \%$ confidence. A twotailed pared T-test used to assess non-engineers' responses demonstrated p-values of $0.075,1$, 
and 0.203 . While none of these are statistically significant on their own at that threshold either, the responses to the question about synthesizing information remains the closest.

Despite the absence of statistically significant change in the pre- and post- class survey responses, students reported that they found the course to be impactful. In the survey administered after the course, students were asked the following questions:

What kind of impact has your experience in this course had on the comfort you feel synthesizing information from across multiple disciplines?

What kind of impact has your experience in this course had on your ability to plan and implement projects in an interdisciplinary team environment?

Regarding their comfort synthesizing information, the engineers' responses averaged a 4.1 on a 5 point Likert scale and the non-engineers' responses averaged a 4.3, indicating that they rated it between Very and Somewhat Impactful. On the topic of their ability to plan and implement projects in an interdisciplinary environment, both engineering students and non-engineering students averaged a 4.3 on a 5 point Likert scale (see Table 3 ) indicating that they considered the course impactful for their abilities.

Table 3: Students' reflections on the impact that the course had for them.

\begin{tabular}{|l|l|l|}
\hline & $\begin{array}{l}\text { What kind of impact has } \\
\text { your experience in this } \\
\text { course had on the } \\
\text { comfort you feel } \\
\text { synthesizing } \\
\text { information from across } \\
\text { multiple disciplines? }\end{array}$ & $\begin{array}{l}\text { What kind of impact } \\
\text { has your experience in } \\
\text { this course had on your } \\
\text { ability to plan and } \\
\text { implement projects in } \\
\text { an interdisciplinary } \\
\text { team environment? }\end{array}$ \\
\hline Engineer Average Post-Class & 4.1 & 4.3 \\
\hline Non-Engineer Average Post-Class & 4.3 & 4.3 \\
\hline
\end{tabular}

As part of the post-survey, students were prompted: "Please reflect on what aspects of this course impacted your ability to plan and implement projects in an interdisciplinary team environment." Most replied by indicating particular exercises, assignments, and processes they were required to complete as part of the course, which we will not report in depth here. It is worth noting, however, that one engineering student responded that what impacted his ability to plan and implement projects was "Actually having to do so. The practice worked better than any exercise."

\section{In-Class Observational Data}

All teams were observed throughout the semester by Drs. Hoople and Choi-Fitzpatrick. While Drs. Hoople and Choi-Fitzpatrick, the instructors of record, were present every day, Dr. Reddy 
only attended six class sessions during which students went to work on their outputs: designing a pro-social drone.

In the busy lab where class met, each team worked differently on their pursuits. The classroom was ideally suited for this course, student teams each had a four person table. These tables were surrounded by various workstations with different tools, such as hand tools and soldering irons. The kinds of work they had did not lend itself to sharing tasks equally or to constant occupation on the part of all students - sometimes a project, like research on one topic or soldering a set of wires, could better be undertaken by only a few team members than all of them. Groups divided to take care of these on working days, and some team members took advantage of the way tasks were divided to slack off, play on computers, or wander away. Others waited intently for their chance to participate, and watched over their teammates' shoulders. They were not always engaged - the tasks they had been assigned did not allow for everyone to participate at once.

Engineers took care to establish informal rules of equity. For example, they ensured nonengineers were involved in building the drone, and that teams shared responsibility for the prosocial design challenge. This meant that they sometimes physically stepped back to direct or coordinate action from a distance. One team made sure that a member who had significant experience with drone building could not touch their drone at all. While there were men and women in both engineer and non-engineer student populations, preliminary data analysis indicates that male engineers tended to participate more physically with drone construction than female engineers or non-engineers of either gender. Further research on gendered dimensions of interdisciplinary teamwork is necessary, though qualitative data below suggests some of the variation had to do with levels of confidence, and previous technical experiences.

\section{Focus Group Data}

All twenty-four students (14 engineers and 10 non-engineers) participated in focus groups in the last week of their classroom experience. Together in their teams, they reflected on the course objectives (that each student learn about working in teams and collaborating while building drones) and team outputs (the jointly-constructed drone and a team-designed plan for a prosocial drone).

A set of themes emerged from student responses to prompts asking them to: 1) discuss their experience working together; 2) discuss course themes and what they felt that they learned; and 3) think about the future, a set of themes emerged.

1) Regarding their experience working together, students described very different kinds of strategies for dividing tasks. In every team, the non-engineers were involved in technical drone 
assembly and the engineers were involved in critical reflection and project planning, but each developed different methods to make sure this was the case.

The strategies that teams developed were suited to their own capabilities and needs. For example, many found it hard to schedule times at which all members could meet. Half the teams $(3 / 6)$, unprompted, discussed the difficulties of scheduling team meetings when members had wildly varying schedules related to their different degree programs. While engineers' classes met during the day, many of the non-engineers, who were graduate student, had classes at night. The strategies that they devised to share work were related to this.

Even when all were present, though, sharing tasks could be challenging. An engineer in one team explained:

Yeah, I feel like I might've taken over a little bit too much, but then once we got to build day like two and three I tried to kind of be like, "All right, this is what we need to do, like I'm going to try to be a little more hands-off," but then, some of it, like when we had to rebuild a couple of times ... I was like, well, I kind of know what was wrong with it ...

It was evident from observations as well as responses in focus groups that splitting the technical work among engineers and non-engineers provided an opportunity for students to try new things. Sometimes, however, practical challenges drove the students with more technical expertise or confidence in this setting to step in and take charge. Preliminary data analysis indicates that those who did so during drone building were often male engineers.

2) When asked to reflect on what they learned in the class, students in most teams $(5 / 6)$ noted that this course was unlike others in their experiences. Although engineering students were required to take courses outside of their discipline as part of the University of San Diego's Liberal Arts educational mission, this kind of work was different. As one engineering student put it, although he had done projects in other classes,

I think it matters a lot based on when I'm with someone else in another class, we're all still working on that class. We're not working on a cross-discipline project, like the actual projects you do are still single disciplined ....

This course offered a different kind of learning opportunity, students suggested. Engineering students in two teams reflected that, while they were often told about the value and necessity of partnerships across disciplines, they rarely got the chance to do it. One said:

I think in like our mechanical engineering classes we always talk, like, 'Oh, you're never going be on a team with just MEs, like that's never going to happen.' But then, in 
everything we do we're on a team with just MEs. And so it's like, okay, well like what's this experience actually going to be like?

Non-engineering students made similar observations. In their ordinary classes, they dealt with critique and theory, but did not often put these into practice. One non-engineer commented:

This class was meaningful for me because at least we moved from analyzing to doing something in reality and that helped a lot. It's given me... hope to [do] a lot of things.

Another engineering student reflected on different perspectives and approaches to problems that this course allowed them to encounter. He saw their non-engineer colleagues' insights as crucial for their projects development, and a testament to the utility of bringing people with different training together to solve problems. Considering these perspectives early in their planning process allowed teams to come up with new ideas or circumvent troubles in later stages of design:

You know, talking with a lot of people in the class seeing how, when you talk to an engineer you get one perspective, and because of the way we've been trained that's usually the same. But when we talk to a Peace and Justice student, I'm like, “Oh, I never thought about all these other possibilities."

Thus, the interdisciplinary interactions led to new insights about the engineering process.

3) In all teams, students reflected that they would take things away from this course that they thought would be useful to them. They commented on learning to reflect on their own disciplinary perspectives. One engineer said that he learned how the engineering mindset he read about in class might have consequences for his work [19]:

...until you like actually, like, talk about it and write it down, you kind of just fall into the trap of it without thinking about it.

This student, and others, were reflecting on their own disciplinary habits, an aspect of interdisciplinary competence identified by Latucca, Knight and Burghom [20] that supports an understanding of the power and utility in working with a diverse team.

The critical perspectives that engineering students encountered in the class could be frustrating, though. One engineering student considered the readings and the difficult position they put him in: 
Okay, we're going to take a technology and use it for ...good..., but there are some people that will use it in [more negative ways] so I was still, like, confused in the middle.

For him, "confused in the middle," uncertain of whether technologies might have net positive or net negative effects, was a difficult place to be with respect to his future. As an engineer, he saw working with and developing new technologies as a key part of his life plan, but some of what he had learned painted technologies in a less than positive light. He was uncertain about what he should do in light of these critical perspectives, and wished that take-aways could be more clear and directive:

This is what I'm doing in the future.... Should I continue doing it?

This student's comments reflect deep engagement with ethical challenges.. Other students also found that the critical insights they were exposed to and the opportunities to work with peers in different disciplines they gained in this class were going to be useful in facing future challenges. Engineering students in some teams (2/6) thought that the skills they learned would be applicable in their senior capstone project, but others were thinking farther into the future, to the jobs they hoped to have. Many of the students discussed skills they were acquiring. As one non-engineer put it:

I think this class taught us how, like the realistic working space would be with people from different backgrounds, different technical backgrounds, or non-technical backgrounds. So, I think it was a good example of how it will be once we finish school and we go like start to work a job. How to work with each other and capitalize on peoples' strengths.

Here, the student is putting course skills in context. She is addressing her understanding of the working world, and highlighting the ways she expects experience from the course to be helpful in her future life. Her reflection makes several assumptions that it are worth noting: first, that her workplace will be diverse - a key issue that students often overlook — and secondly, that such diversity is a strength to be "capitalized" on, rather than a challenge to be overcome.

\section{Discussion and Conclusion}

Students came to this course with some knowledge of their different disciplines and programs. They were also fairly confident in their abilities to use the conceptual equipment that their discipline or degree program was teaching them. They were confident about quite a bit: in the survey they took as their course began, they indicated confidence in their abilities to work with people in other disciplines. 
While these responses to questions regarding working with teammates trained in disciplines different than their own remained fairly consistent between pre- and post-class surveys, students also suggested that their experiences in the class had impacted them in ways that their quantified responses to survey questions simply could not reflect. The focus groups provided opportunities to dig deeper, and observations lend context to the students' narratives shared in focus groups. There, we learned that while students knew that teamwork with people trained in different disciplines would be important for them in their futures, few engineers or non-engineers had taken classes that gave them opportunities to practice it in ways they could directly associate with their career goals. These skills are crucial to engineering students' future success, as ABET requirements suggest.

This course offered something different - two outputs that engineers and non-engineers alike could focus on, which presented them with challenges to share, and which all students could bring different kinds of insights and skills to bear on. Working through the drone build and the pro-social design exercise gave them situated experience in managing teams. Students discussed some of the troubles that this could present in the focus groups when they addressed different divisions of labor and the trouble that they had with scheduling. They also discuss both the utility and challenges of incorporating substantive contributions from across disciplines.

Division of labor and active participation in the course's two objectives could be hard to track from minute to minute. The work in which they were engaging required some students to take a back seat from time to time, and different students exhibited different forms of engagement. It seems likely that not every part of the process could be completely interdisciplinary. Requiring all students to participate was a good method for teambuilding. However, sustained observation indicated that while some students did participate, and were active in the development of the two outputs of the course, others engaged less. It could be argued that those who were not active in the outputs still supported course outcomes, as their teammates learned to navigate task divisions in less-than-ideal circumstances that might, indeed, reflect the kinds of conditions they will navigate as professionals. Future observational data is needed to examine disciplinary and gendered trends in participation.

Some students' reflections indicate that they experienced real transformation in this class, including new insights into their own ideas and practices and interdisciplinary transformationthe engineer who suggested in the focus group that he will think about the work he wants to do with his life differently and the Peace Studies student who reflected that she was interested in moving "from analyzing to doing" after this course might exemplify this kind of transformation. Some students' reflections demonstrate they developed skills for working in multidisciplinary environments and coordinating different forms of contribution. There are potential trends to be explored here, and it would be worth investigating if distinctions can be made between engineers or non-engineers on this front. 
Next steps for this project include refinement of the syllabus for a weekend workshop format as well as a course offering in Fall 2018, and further data collection and analysis. The outputs that students developed - both the drones and their plans for pro-social payloads, seem interdisciplinary, as all contributed to them, but will require more evaluation. How has this challenging, productive framework helped students learn about interdisciplinary collaboration and gain new insights about their own fields? Evaluating student essays and reflections on team work as well as survey, focus group, and observational data will contribute to more substantial conclusions regarding the impact of this class. Faculty are confident in the potential of the course and they continue to make iterative adjustments to enhance the group dynamics.

Further evaluation of this data and data from future iterations of the course will engage more robustly with the dimensions of interdisciplinary competence identified by Lattuca, Knight and Burghom [20]. Future iterations of the course may incorporate Lattuca, Knight and Burgom's Measure of Interdisciplinary Competence for Engineers or the Cross Disciplinary Team Learning Efficacy scale developed by Scahffer, Huyck, Oakes and Gandara [21]. We seek to address how educational experience, material objects, interpersonal interaction, and contextual factors are inextricably part of learning along with instruction that might prompt a student to reflect that the benefit of the course work was doing it: that, as a student indicated in his survey response "the practice worked better than any exercise."

\section{References}

[1] G. L. Downey. "What Is Engineering Studies for? Dominant Practices and Scalable Scholarship.” Engineering Studies vol. 1, no, 1, 2009, p. 61.

[2] National Academy of Engineering. Educating the Engineer of 2020: Adapting Engineering Education to the New Century. Washington D.C.: National Academy Press, 2005.

[3] ABET. Criteria for accrediting engineering programs effective for the evaluations during the 2018-2019 accreditation cycle. http:/www .abet.org/accreditation/accreditation-criteria/criteriafor-accrediting-engineering-programs-2018-2019/ [accessed Feb. 4, 2018]

[4] J. Lave, and E. Wenger. Situated Learning. Legitimate Peripheral Participation. Cambridge: University of Cambridge Press, 1991.

[5] A. Johri, and B. M. Olds. "Situated Engineering Learning: Bridging Engineering Education Research and the Learning Sciences.” Journal of Engineering Education vol. 100, no. 1, 2011, pp. 151-85. 
[6] L. D. McNair, M. Davitt, and G. P. Batten. "Outside the 'Comfort Zone': Impacts of Interdisciplinary Research Collaboration on Research, Pedagogy, and Disciplinary Knowledge Production.” Engineering Studies vol. 7, no. 1, 2015, pp. 47-79.

[7] L. R. Lattuca. Creating Interdisciplinarity: Interdisciplinary Research and Teaching Among College and University Faculty. Nashville, TN: Vanderbilt University Press, 2001.

[8] M. Borrego and L. K. Newswander. "Characteristics of Successful Cross-Disciplinary Engineering Education Collaborations." Journal of Engineering Education vol. 97, no. 2, 2008 p. 124.

[9] J. T. Klein. Interdisciplinarity: History, Theory, and Practice. Detroit, MI: Wayne State University Press, 1990.

[10] L. R. Lattuca, D. B. Knight, H. K. Ro, and B. J. Novoselich. "Supporting the Development of Engineers' Interdisciplinary Competence." Journal of Engineering Education vol. 106, no. 1, 2017, pp. 71-97.

[11] J. A. Jacobs. In Defense of Disciplines: Interdisciplinarity and Specialization in the Research University. Chicago, IL: University of Chicago Press, 2014.

[12] A. Kedrowicz and B. Nelson. "Dramatizing Engineering Education: The Performance of Teamwork." American Society For Engineering Education Annual Conference Proceedings, Honolulu, HI, June 24-27, 2007.

[13] D. C. Llewellyn, P. Pyke, S. Paterson, R. E. Landrum, A. Scarritt, J. B. S. Cullers, and D. L. Warner. "Better Together: Connecting with Other Disciplines Builds Students' Own Skills and Professional Identity." American Society For Engineering Education Annual Conference Proceedings, New Orleans, LA, June 26-29, 2016.

[14] A. Hurst, E. Jobidon, A Prier, T. Khaniyev, C. Rennick, R. Al-Hammoud, C. Hulls, et al. "Towards a Multidisciplinary Teamwork Training Series for Undergraduate Engineering Students: Development and Assessment of Two First-Year Workshops." American Society For Engineering Education Annual Conference Proceedings, New Orleans, LA, June 26-29, 2016.

[15] A. Choi-Fitzpatrick "Drones for Good: Technological Innovations, Social Movements, and the state." Journal of International Affairs 2014, pp. 19-36. 
[16] G. Hoople and A Choi-Fitzpatrick "Engineering Empathy : A Multidisciplinary Approach Combining Engineering, Peace Studies, and Drones." American Society For Engineering Education Annual Conference Proceedings, Columbos, OH, June 25-28, 2017.

[17] H.R. Bernard. Research Methods in Anthropology: Qualitative and Quantitative Approaches. 4th ed. Maryland: AltaMira Press, 2005.

[18] D. Dunning. "The Dunning-Kruger Effect: On Being Ignorant of One’s Own Ignorance." Advances in Experimental Social Psychology vol. 44, 2011, pp. 247-96.

[19] D. Riley. Engineering and Social Justice. San Rafael, CA: Morgan and Claypool. 2008.

[20] L. R. Lattuca, D. B. Knight, and I. M. Bergom. "Developing a Measure of Interdisciplinary." American Society For Engineering Education Annual Conference Proceedings, San Antonio, TX, June 10 - 13, 2012.

[21] S. P. Schaffer, M Huyck, W. C. Oakes, and D. Gandara. "Assessing Teamwork and Best Educational Practices in Undergraduate Multidisciplinary Teams.” American Society For Engineering Education Annual Conference Proceedings, Vancouver, BC, Canada June 26 - 29, 2011. 